\title{
OPTIMIZING ASPHALT MIXTURES TO BE HEATED BY MICROWAVES
}

\author{
J. Gallego ${ }^{1}$, F. Gulisano ${ }^{1}$, L. Picado ${ }^{2}$, J. Crucho ${ }^{2}$, \\ ${ }^{1}$ Technical University of Madrid,C/ Profesor Aranguren 3, Madrid, Spain \\ ${ }^{2}$ CERIS, Instituto Superior Tecnico, U. de Lisboa,. Avda. Rovisco Pais 1, Lisbon, Portugal \\ juan.gallego@upm.es
}

Keywords: microwave, heating, asphalt mixtures, self-healing

\begin{abstract}
Over the last ten years the concept of self-healing in asphalt mixtures for road pavements has been reaching great importance due to the fact that this capability allows a material to recuperate original properties after failure. This new generation of asphalt paving materials would allow road agencies to save no renewable resources as aggregates and bitumen, making the road investments more efficient.

Probably the most promising method for the in-situ heating of the pavements is the radiation by microwaves. By heating the pavement, the asphalt binder gets melt and refills the cracks in the material, recuperating a part of its initial structural parameters. Unfortunately, asphalt mixture components (aggregates and binder) are low sensitive to microwave energy. This is why it may be advantageous to incorporate in the mixture additives to improve the sensibility to the radiation with microwaves.

In this investigation two additives were studied: graphene and electric arc furnace (EAF) slag coming from the steel industry. These additives were incorporated at several contents and the efficiency of the heating process was evaluated by the ratio ${ }^{\circ} \mathrm{C} / \mathrm{kwh} / \mathrm{kg}$ in order to optimize the content of the additive in the asphalt mixture.

Additionally, an evaluation of the electrical conductivity of the asphalt mixture at different contents of additives were carried out to study the possible relation between the conductivity of the mixture and its sensibility to microwave radiation.

As a result of the investigation, it seems that microwave radiation can be a real option to promote in situ self-healing of asphalt pavements.
\end{abstract}

\section{Introduction}

Asphalt mixture is the most common material used for road pavement construction in the world and is composed of aggregates and bitumen. However, traffic loads combined with environmental conditions deteriorate asphalt pavement. Cracking is one of the most common sign of asphalt mixture distress, and is caused by cycling loading (fatigue), bitumen aging (oxidation) and temperature variation [1]. Such a damage reduces the mechanical strength and the durability over time [2], and affects the safety of driving [3]. As a result, the pavement should be regularly maintained to restore its original properties. Fortunately, asphalt mixture is a self-healing material, and its healing properties are directly linked to temperature and to the rest periods [4]. When the asphalt pavement is exposed to a temperature above a certain threshold (between $50{ }^{\circ} \mathrm{C}$ and $70{ }^{\circ} \mathrm{C}$ ), bitumen starts behaving as a Newtonian fluid and can flow through the cracks, filling them. This phenomenon can be explained by the diffusion of the molecules between the two sides of the crack, which would create connection points that partially restore the continuity of the material [5]. Such a technology permits increasing the lifetime of the pavement and will also lead savings of 
$\mathrm{CO}_{2}$ emission and less energy consumption for production and maintenance pavements [6]. However, natural self-healing process may require several days to restore the original properties of the pavement, which in practice is impossible due to traffic flow and weather conditions. For this reason, in the last years several researchers proposed different technology with the aim of accelerating the self-healing process. One of the most promising technologies is the microwave heating. Microwave radiation has found different applications in pavement engineering, such as recycling of asphalt pavement [7] and deicing application [8] [9], although most of the researchers used microwave heating to promote self-healing process [10][11][12][13][14][1]. When asphalt mixture is exposed to microwave radiation, heat is generated through conversion of the energy of the electromagnetic field [15]. Under the influence of an alternative electromagnetic field, the polar molecules of asphalt mixture attempt to line up (polarize) with the field. The motion of these molecules is limited by inertia and resisting forces which restrict the motion of molecules and generate random motion and inter-molecular friction that produces heat [7]. Unfortunately, the microwave heating efficiency of ordinary asphalt mixture is very low, due to the low microwave absorbing properties, and for this reason some researchers utilized different additives to improve microwave absorbing properties of asphalt mixture [16], such as steel wool [11] [12], steel slag [17] [13], ferrite [14] and carbon nanotubes [18]. The efficiency of a material in absorbing microwave energy can be described by its dielectric properties [19], usually expressed by the complex permittivity:

$$
\varepsilon^{*}=\varepsilon^{\prime}-i \varepsilon^{\prime \prime}
$$

where $\varepsilon^{\prime}$ is the dielectric constant, representing the amount of energy that can be stored in the material in the form of electric field, $\varepsilon$ " indicates how much of that energy a material can dissipate in the form of heat. Another parameter used for determining the microwave absorbing efficiency is the loss tangent:

$$
\tan \delta=\sigma_{s} /\left(\omega \varepsilon^{\prime}\right)+\varepsilon^{\prime \prime} / \varepsilon^{\prime}
$$

It can be expressed as a sum of two terms [20]: The first term, $\sigma_{s} /\left(\omega \varepsilon^{\prime}\right)$, depends on the conductivity of the material $\left(\sigma_{s}\right)$, and describes loss due to collisions of electrons with other electrons, while the second term, $\varepsilon$ "' $\varepsilon$ ' describes how much energy supplied by an external electric field is dissipated as motion and heat. In conductors, the first term dominates the second, while in dielectrics the second term dominates the first. Semiconductors maintain a relative balance between the two terms. In the case of asphalt mixture dielectric properties are affected not only by frequency and temperature, but also by other properties of the mixture, such as density, moisture and type of aggregates [21]. Several researchers have simulated the electro-magneto-thermal phenomenon of microwave heating in asphalt mixture by using different simulation models, and different parameters have been considered, such as complex permittivity, complex permeability and some thermal properties [15] [8][17][7].

In this research, two kind of additives were studied with the aim of optimizing the microwave heating efficiency: Graphene and Electric Arc Furnace (EAF) Slag. The efficiency of the microwave heating process has been evaluated in terms of the ratio ${ }^{\circ} \mathrm{C} / \mathrm{kWh} / \mathrm{kg}$. This is, the increase of temperature $\left({ }^{\circ} \mathrm{C}\right)$ achieved by the radiation of $1 \mathrm{~kg}$ of asphalt mixture with $1 \mathrm{kWh}$ of microwave energy in fixed conditions. Asphalt mixtures were prepared with different contents of additive, in order to find the optimum percentage in terms of energy efficiency. Additionally, an evaluation of the electrical resistivity of the asphalt mixture at different contents of additives were carried out to study the possible relation between the conductivity of the mixture and its sensibility to microwave radiation. This technology is a promising 
field in the sector of microwave heating applications, although it has not been deeply explored.

\section{Materials}

In total, eight different asphalt mixtures were manufactured in the study: one reference mixture without additives; three asphalt mixture with EAF slag in different contents by total volume of aggregates $(3 \%, 6 \%$ and $9 \%)$; four asphalt mixture with graphene in different contents by total mass of bitumen $(0.5 \%, 1 \%, 1.5 \%$ and $2 \%)$. A conventional asphalt mixture AC20 35/50 was chosen as reference. It was manufactured with limestone aggregates, and its particle size composition is presented in Table 1 . The bitumen content of all the mixtures was $4.6 \%$ by weight of aggregate. Cylindrical specimens (approximately $100 \mathrm{~mm}$ in diameter and $60 \mathrm{~mm}$ in height) were prepared at $165^{\circ} \mathrm{C}$ and then compacted with a Marshall hammer (EN 12697-30: Specimen preparation by Impact compactor) applying 75 bowls on each side at $155^{\circ} \mathrm{C}$. Two Slag fractions were used to replace limestone aggregates: 2/0.5 $\mathrm{mm}$ and $0.5 / 0.063 \mathrm{~mm}$. The chemical composition of EAF slag is reported in Table 2 . Graphene Nanoplatelets (GRAPHENIT-XL) with a bulk density of $0.04 \mathrm{~g} / \mathrm{ml}$ was used, and the elemental analysis is reported in Table 3.

Table 1. Grading curve of the asphalt mixtures

\begin{tabular}{cccccccc}
\hline Sieve $(\mathrm{mm})$ & 22 & 16 & 8 & 4 & 2 & 0.5 & 0.063 \\
$\%$ Passing & 100 & 83 & 56 & 42 & 34 & 19 & 5 \\
\hline
\end{tabular}

Table 2. Chemical composition of EAF slag

\begin{tabular}{cc}
\hline Chemical composition & $\%$ \\
\hline $\mathrm{Al}_{2} \mathrm{O}_{3}$ & 8.81 \\
$\mathrm{CaO}$ & 24.28 \\
$\mathrm{Fe}_{2} \mathrm{O}_{3}$ & 40.49 \\
$\mathrm{MgO}$ & 3.02 \\
$\mathrm{MnO}$ & 4.72 \\
$\mathrm{SiO}_{2}$ & 12.60 \\
$\mathrm{P}_{2} \mathrm{O}_{5}$ & 0.36 \\
Other substances & 5.72 \\
\hline
\end{tabular}

Table 3. Elemental Analysis of Graphene

\begin{tabular}{cc}
\hline Chemical composition & $\%$ \\
\hline $\mathrm{C}$ & 96.41 \\
$\mathrm{H}$ & 0.07 \\
$\mathrm{~N}$ & 0.48 \\
$\mathrm{~S}$ & 0.48 \\
$\mathrm{O}$ & 1.05 \\
\hline
\end{tabular}




\section{Methods}

\subsection{Microwave heating}

To heat the asphalt mixture specimens, a microwave oven was used with an output of $1200 \mathrm{~W}$ and a $230 \mathrm{~V}, 50 \mathrm{~Hz}$ power supply. The oven can produce microwaves of up to $700 \mathrm{~W}$ with a frequency of $2.45 \mathrm{GHz}$. However, in this research a medium power of $350 \mathrm{~W}$ was used. The asphalt mixture specimens were cut into two semi-cylindrical halves; then, both pieces were placed together in the oven and heated for five heating times: $30 \mathrm{~s}, 60 \mathrm{~s}, 90 \mathrm{~s}, 120 \mathrm{~s}$ and 150 s. After each heating time the internal temperatures were measured with an infrared gun. Eight temperatures were taken, randomly chosen in the test sample, and the average was calculated. The initial air temperature was $25^{\circ} \mathrm{C}$. Additionally, an electricity meter was used to measure the energy consumption of the oven during the heating of the specimens. The microwave heating process is shown in Fig. 1.

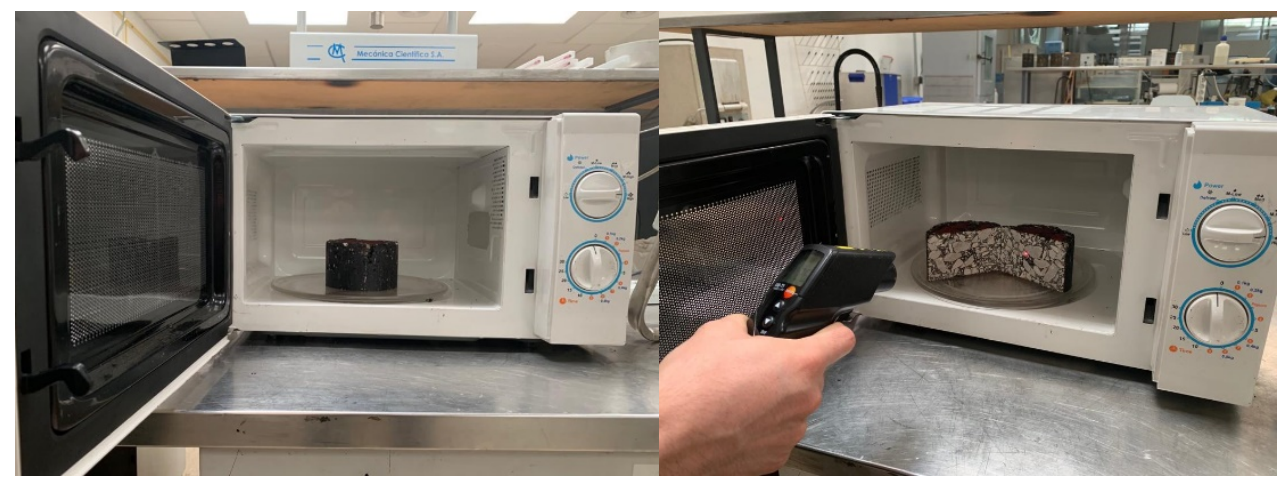

Fig. 1. Asphalt mixtures heating.

\subsection{Electrical resistivity}

The electrical resistance of the asphalt mixtures was measured with the two-probe method by using a megohmmeter with 5 ranges $(50 \mathrm{~V}-1000 \mathrm{~V})$. The asphalt specimen, with a thickness of $\sim 4 \mathrm{~cm}$ was placed between two copper plate electrodes with dimensions $15 \mathrm{x}$ $15 \mathrm{~cm}$ connected with the megohmmeter. Graphene powder was used to fill the gaps between the plate electrodes and the specimens and to ensure a perfect contact between them. The selected voltage was applied to each asphalt specimen for 5 minutes, and then the measurement was taken, as shown in Fig. 2. The electrical resistivity was calculated applying the second Ohm's law:

$$
\rho=(R \cdot S) / l(3)
$$

Where $R$ is the electrical resistance of each specimen in $\Omega ; S$ is the electrode-specimen contact area measured in $\mathrm{m}^{2}$ and $l$ is the thickness of the asphalt sample in $\mathrm{m}$. 

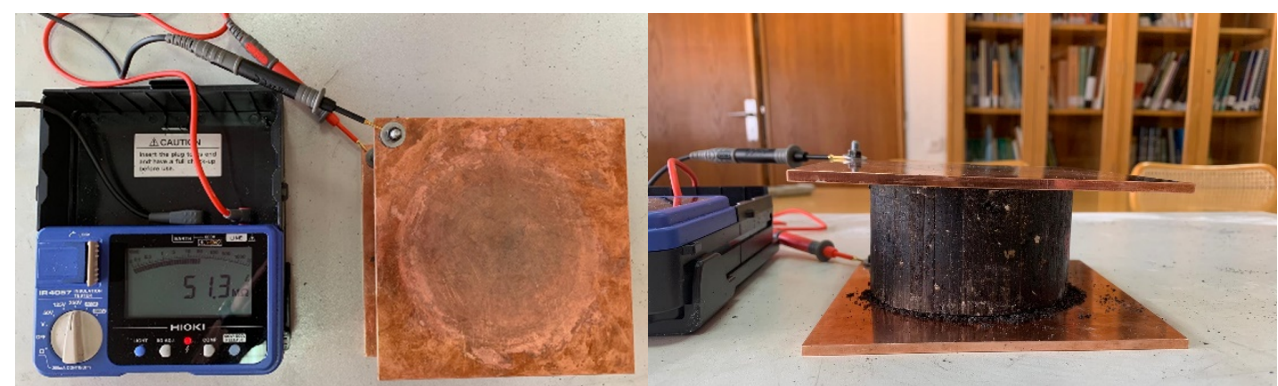

Fig. 2. Measurement of the electrical resistivity of asphalt specimens

\section{Results}

\subsection{Heating efficiency}

Fig. 3 shows the relationship between the internal temperature of the asphalts mixtures and the total energy consumed during the heating. As can be seen, adding EAF slag or graphene to the asphalt mixture produce an increase in the heating efficiency, in terms of the ratio ${ }^{\circ} \mathrm{C} / \mathrm{kWh} / \mathrm{kg}$. The higher the amount of additive, the faster the temperature increase with energy. For a total energy of $0.03 \mathrm{kWh} / \mathrm{Kg}$, corresponding to a heating time of $150 \mathrm{~s}$, the asphalt mixture with $9 \%$ of slag reaches $88{ }^{\circ} \mathrm{C}$, while the mixture with $2 \%$ of graphene reaches $95{ }^{\circ} \mathrm{C}$. On the contrary, the reference mixture (with no additives) reaches $60{ }^{\circ} \mathrm{C}$
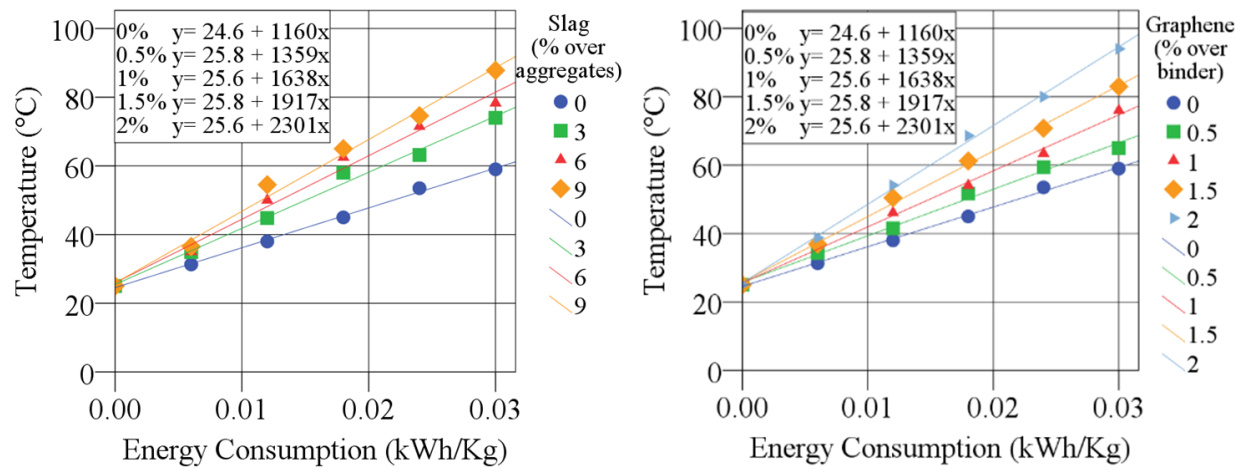

Fig. 3. Temperature analysis of asphalt mixtures with (a) EAF slag and (b) with graphene

However, two aspects must be considered when adding slag or graphene in the asphalt mixtures: the cost and the mechanical performance of the mixtures. The inclusion of EAF slag doesn't imply additional cost, as the cost is similar to the prices of natural aggregates [16], and the mechanical behavior of mixtures with steel slag aggregate is generally better than that of the samples with natural aggregate [22]. In contrast, the addition of graphene is very expensive, and there are currently very few studied about the mechanical performance of these kind of mixtures.

\subsection{Electrical resistivity}

Fig 4 shows the electrical resistivity of the asphalt mixture specimens with different contents of EAF slag and graphene. The inclusion of additives produces a decrease in the electrical 
resistivity of the mixture, and therefore an increase in the electrical conductivity. As for the slag, by adding a total amount of $6 \%$ to the mixture, the benefit in terms of electrical resistivity reduction is not very high, while a substitution of $9 \%$ allows to obtain a value of $1.7 \times 10^{6} \Omega \cdot \mathrm{m}$, corresponding to a total reduction of $99 \%$ respect to the reference mixture $\left(2.3 \times 10^{8} \Omega \cdot \mathrm{m}\right)$. The resistivity of the mixtures containing graphene slightly decrease with the increase of additive content, until reaching a value of $1.3 \times 10^{8} \Omega \cdot \mathrm{m}$ by adding $2 \%$ of graphene. Comparing these results with the ones obtained with the heating curves, it seems that the electrical conductivity of the mixture has not a direct relationship with the heating efficiency. Further research must be conducted to analyze the influence of other parameters, such as the complex permittivity, complex permeability and thermal properties of the asphalt mixture.
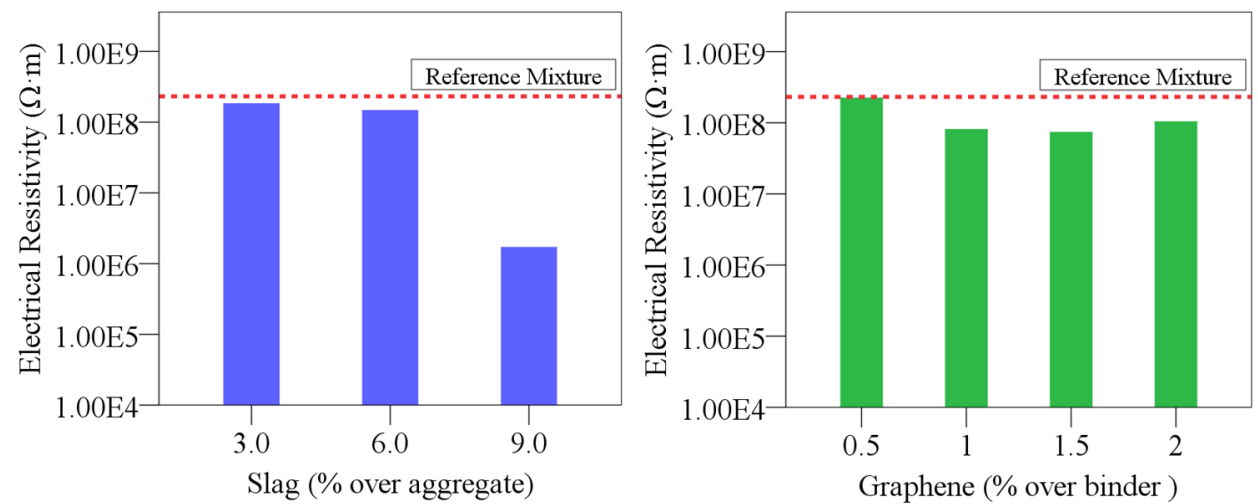

Fig. 4. Electrical resistivity of asphalt mixtures with (a) EAF slag and (b) with graphene

\section{Conclusion}

In this paper, EAF slag and graphene were incorporated in the asphalt mixture, in order to increase the microwave heating efficiency. From the results obtained, several conclusions can be drawn. Both additives produce an increase in the microwave heating efficiency, in terms of the ratio ${ }^{\circ} \mathrm{C} / \mathrm{kWh} / \mathrm{kg}$. However, the lower price of EAF slag compared with graphene makes preferable the use of slag for these applications from an economic point of view. In future research, a comparison between the mechanical performance and the selfhealing properties of the two additives should be conducted beyond the heating properties showed in this investigation.

Additionally, an evaluation of the electrical resistivity of the asphalt mixture at different contents of additives were carried out to study the possible relation between the conductivity of the mixture and its sensibility to microwave radiation. The inclusion of additives produces a decrease in the electrical resistivity of the mixture, and the addition of $9 \%$ of EAF slag provide the best benefits in terms of resistivity reduction. However, the results show that this parameter is not directly related to the microwave heating efficiency. In future research, dielectric and thermal properties of the mixture should be analyzed, in order to study the microwave absorption properties of asphalt mixtures. In conclusion, the use of microwave energy for heating purpose is a very promising technology for asphalt pavement engineering. 


\section{Acknowledgments}

The collaboration for this investigation between the University of Lisbon and the Technical University of Madrid was possible thanks to Grant n. PDI-18-0HXIUI-55-QZMWQL for Investigation Stays of Senior Researchers in Foreign Universities and an additional Grant for PhD students by the Agustín of Betancourt Foundation.

\section{References}

[1] A. Gonzalez, J. Norambuena-Contreras, L. Storey, and E. Schlangen, "Effect of RAP and fibers addition on asphalt mixtures with self-healing properties gained by microwave radiation heating," Constr. Build. Mater., vol. 159, pp. 164-174, 2018.

[2] J. Norambuena-Contreras, R. Serpell, G. V. Vidal, A. Gonzalez, and E. Schlangen, "Effect of fibres addition on the physical and mechanical properties of asphalt mixtures with crack-healing purposes by microwave radiation," Constr. Build. Mater., vol. 127, pp. 369-382, 2016.

[3] C. Li, S. Wu, Z. Chen, G. Tao, and Y. Xiao, "Enhanced heat release and self-healing properties of steel slag filler based asphalt materials under microwave irradiation," Constr. Build. Mater., vol. 193, pp. 32-41, Dec. 2018.

[4] Á. García, "Self-healing of open cracks in asphalt mastic," Fuel, vol. 93, pp. 264-272, Mar. 2012.

[5] D. N. Little and A. Bhasin, "Exploring Mechanism of Healing in Asphalt Mixtures and Quantifying its Impact," Springer, Dordrecht, 2007, pp. 205-218.

[6] Q. Liu, Á. García, E. Schlangen, and M. van de Ven, "Induction healing of asphalt mastic and porous asphalt concrete," Constr. Build. Mater., vol. 25, no. 9, pp. 3746-3752, Sep. 2011.

[7] A. Benedetto and A. Calvi, "A pilot study on microwave heating for production and recycling of road pavement materials," Constr. Build. Mater., vol. 44, pp. 351-359, Jul. 2013.

[8] L. Ding, X. Wang, W. Zhang, S. Wang, J. Zhao, and Y. Li, "Microwave Deicing Efficiency: Study on the Difference between Microwave Frequencies and Road Structure Materials," Appl. Sci., vol. 8, no. 12, p. 2360, Nov. 2018.

[9] Y. Sun, S. Wu, Q. Liu, J. Hu, Y. Yuan, and Q. Ye, "Snow and ice melting properties of self-healing asphalt mixtures with induction heating and microwave heating," Appl. Therm. Eng., vol. 129, pp. 871-883, Jan. 2018.

[10] J. Norambuena-Contreras, A. Gonzalez, J. L. Concha, I. Gonzalez-Torre, and E. Schlangen, "Effect of metallic waste addition on the electrical, thermophysical and microwave crack-healing properties of asphalt mixtures," Constr. Build. Mater., vol. 187, pp. 1039-1050, 2018.

[11] J. Gallego, M. A. del Val, V. Contreras, and A. Paez, "Heating asphalt mixtures with microwaves to promote self-healing," Constr. Build. Mater., vol. 42, pp. 1-4, 2013.

[12] J. Norambuena-Contreras and A. Garcia, "Self-healing of asphalt mixture by microwave and induction heating," Mater. Des., vol. 106, pp. 404-414, 2016.

[13] T. M. Phan, D.-W. Park, and T. H. M. Le, "Crack healing performance of hot mix asphalt containing steel slag by microwaves heating," Constr. Build. Mater., vol. 180, pp. 503-511, Aug. 2018.

[14] X. Zhu, Y. Cai, S. Zhong, J. Zhu, and H. Zhao, "Self-healing efficiency of ferrite-filled asphalt mixture after microwave irradiation," Constr. Build. Mater., vol. 141, pp. 12-22, Jun. 2017.

[15] H. Wang, Y. Zhang, Y. Zhang, S. Feng, G. Lu, and L. Cao, "Laboratory and Numerical 
Investigation of Microwave Heating Properties of Asphalt Mixture," Materials (Basel)., vol. 12, no. 1, p. 146, Jan. 2019.

[16] J. Gallego, M. A. Del Val, V. Contreras, A. Páez, and A. Páez, "Use of additives to improve the capacity of bituminous mixtures to be heated by means of microwaves," Mater. Construcción, vol. 67, no. 325, p. 110, Feb. 2017.

[17] W. Liu, P. Miao, and S.-Y. Wang, "Increasing Microwave Heating Efficiency of Asphalt-Coated Aggregates Mixed with Modified Steel Slag Particles," J. Mater. Civ. Eng., vol. 29, no. 10, p. 04017171, Oct. 2017.

[18]I. Pérez et al., "Self-healing of asphalt mixes, containing conductive modified bitumen,using microwave heating," in 6th Eurasphalt \& Eurobitume Congress, 2016.

[19] A. A. Al-Ohaly and R. L. Terrel, Effect of microwave heating on adhesion and moisture damage of asphalt mixtures. 1988.

[20] C. Bishop, "The Relationship Between Loss, Conductivity, and Dielectric Constant." 2001.

[21] E. J. Jaselskis, J. Grigas, and A. Brilingas, "Dielectric Properties of Asphalt Pavement," J. Mater. Civ. Eng., vol. 15, no. 5, pp. 427-434, Oct. 2003.

[22] M. Skaf, J. M. Manso, Á. Aragón, J. A. Fuente-Alonso, and V. Ortega-López, "EAF slag in asphalt mixes: A brief review of its possible re-use," Resour. Conserv. Recycl., vol. 120, pp. 176-185, May 2017. 